\title{
Effective Deployment of ICT's in Management of Medical Laboratory Services in Kenya
}

\author{
${ }^{1}$ Kadima Victor Chitechi, ${ }^{2}$ Kelvin K. Omieno \\ Masinde Muliro University of science and technology [MMUST] \\ ${ }^{2}$ Kaimosi Friends University College
}

\begin{abstract}
Automation of ICT services has been regarded as a key driver and enabler to better service delivery to most organizations today. Recent demand and access to modern technology have led to improved management of medical laboratory services in Kenya. In Kenya, Health services delivery is being transformed by advancements in technologies embraced thus act as the main support to better medical laboratory services. The paper discusses the state of computer use by medical laboratory facilities, the challenges and emerging technologies used. Various laboratory facilities have automated their services few have initiated the process for better client management, Some facilities are still facing challenges caused by manual systems, such systems need to be phased out to reduce any risks that might be caused by them. The advantage of Computerising a medical facility is that there will be improved growth and proper management of health services by facilities and services to customers. Previous research journals and conference proceedings have been used in this paper as main sources of literature as per the title. Methodological approaches used to get the data from the health facilities are highlighted and explained to show the state of adoption. Findings from previous and current studies indicate that medical facilities have been fully automated; however, the potential for its growth is enormous due to implementation challenges fueled by the rapid demand and penetration of various systems in health facilities.
\end{abstract}

Keywords:- Computerisation, ICT, Automation, Facility, ehealth, health facility, laboratory.

\section{INTRODUCTION}

Advancements in technology has influenced a lot in today's modern society. This has realised a tremendous growth by most organisations who have embraced ICT hence increased economic and social activities. Organisations that have implemented use of modern technology in their daily operations have achieved in their targets, have exhibited better job satisfaction, better service delivery to both clients and stakeholders (Vershima, 2016).

It is important for any firm or organisation and all the stakeholders that they are aware of the trending information on time as it comes; however, there are numerous challenges exhibited by firms and stakeholders on how to access electronic data, information in libraries, resource centers, lack of awareness, such challenges can only be managed by implementing new technologies (Vershima, 2016).

Use of modern technologies to inform users or clients at work depends with how well your firm has invested in technological infrastructure, made users aware, and mobilizing entire organisation on the importance of information (CN Kamau, 2010) . Most developing countries have initiated the process of building capacities in their ICT staff and users as a strategy to reduce the gap in adoption of new technologies. It is evidenced that at such stages many firms are yet to start implementations due to inadequacies in the required skills of the staff and users thus they cannot realise their relevance, applicability or cost effectiveness (Jiang, 2017).

However, both national and county governments have since devolved the entire health function to ensure faster, convenient and better service delivery to society, some of the initiatives being implemented are; setting up target projects for society such as $50 \%$ less rates in mortality/ 25$100 \%$ percent access to healthcare systems. World Health Organisation noted that health sectors globally should rely on technologies since it can be used to make diagnostics and give real-time results required for treatment. If health facilities can have relevant policies, stable management with good resources and budget plans, this will effectively make them adopt and implement ICTs (Lorenzetti, 2016).

Computer technology use in medical laboratory facilities have enabled the doctors have the capacity to specifically identify a patient's health conditions on time. Technologies such imaging and scanning have made it easy for both patients and doctors to know the state of diagnosed results. [4]. It is relevant for all users of such technologies to be well trained and aware of the operations of the equipment. Operating such equipment's need vast knowledge and skills, currently information delivery has become faster due to the introduction of technologies such as cell-phones, social-media, electronic-mail, skype, paging devices and videoconferencing (Laufman H. , 2010). People have been able to communicate and share information through other commonly used ways of delivering digital information that is inform of graphics and sound can be done via use of radio stations, Televisions, recorded video, storage disk players and internet access (Laufman H. , 2010). 
In this paper, the author defines the term electronic Health use of computer technology to operationalize healthcare processes through result process [14]. Common examples of Electronic -Health that comprises modern systems include electronic records, tele-medicine, health information systems, mobile devices, e-learning tools, and decision support systems (Luic, 2005).

In order to lower medical costs, improve the quality and expand the access to health facilities, most developing countries' are using this as a strategy to implement Health Information Systems (HIS) (Sahay M. , 2010). Previous studies had indicated various challenges experienced by the manual systems hence the need to introduce computerised systems which more reliable and efficient (Mndeme N. , 2011). A medical laboratory that has computerised its operations can be able to achieve the following; real-time results, accurate results, better decision-making on patient's medication and improve operating efficiency, this will influence positively on the growth and quality of laboratory services [13].

Earlier studies noted that in achieving better service delivery by any medical facility such as a laboratory, there is need to computerise the entire operation. The key challenge faced during implementation of new technologies include; inadequate resources, unskilled personnel, and infrastructural barriers to e-Health implementation in developing countries, indicates that internet connectivity is vital for successful use of technology in Health. Previous researches conducted on medical practitioners in Kenya had indicated that majority of Kenyan doctors are willing to conduct e-searches in order to access and share health information with their colleagues globally this has even improved further since mist the Doctors today are today learning and utilizing e-research as a tool. However, insufficient ICT resources limit them in performing the searches. In achieving the goal of this title in the paper the following objectives will be discussed; establish the state of computer use in the management of medical laboratory services in Kenya, establish the challenges facing implementation of ICT in the management of medical laboratory services in Kenya and lastly highlight modern technologies used to improve management of medical laboratory services in Kenya.

\section{DEFINING OF TERMS}

Information and Communication Technology (ICT) is a technological term that has various meaning depending with the function. This paper will refer to the term by the following authors [1], [2], [6], and [15]. Most authors have defined ICT with relevant to new or latest technologies. Others have included previous technologies, such as radio or television. For example, ICT can be a tool used in relaying information that is already produced through available mediums, use of technology to diagnosis of samples from patients. The information will include both analogue and digital data, broadcasting media, telecommunication devices, Desktop computers, multimedia systems and internet. ICT use has influenced the society knowledge and access to technology thus improved information delivery globally. However, the scope of technology use in health extends much beyond communication and health itself. Use of new technologies in medical laboratories as health facilities and in various researches being carried out in medical field globally and training are just some of the fields, which have largely benefited from the growth of information and communication technology [19].

\section{$>$ Problem Statement}

Medical laboratories in health facilities have computerised their operations while some are still in the initial process of embracing ICT as a tool in managing their operations, existing systems such as the manual systems had adverse limitations such as poor record management, lack of better planning strategies, loss of records, inaccurate results, and time wastage, In order to counter this challenges medical laboratories must incorporated use of modern technologies such as ICT to eliminate such challenges. Use of computer as a technology in a facility will help to achieve improved growth and proper management of medical laboratory services in developing nations. In solving the existing gap, this paper discusses three issues highlighted that hinder smooth implementation of ICT in health, this includes the current state of computer use, challenges facing the implementation and lastly highlight the various technologies used to improve management of medical laboratories in Kenya.

\section{GENERAL OBJECTIVE}

The main purpose of this paper is to establish the level of ICT use in management of medical laboratory services in Kenya.

\section{Specific Objectives}

The specific objectives are to:

- Establish the state of computer use in the management of medical laboratory services in Kenya

- Establish the challenges facing implementation of ICT in the management of medical laboratory services in Kenya and

- Highlight modern technologies used to improve management of medical laboratory services in Kenya.

\section{METHODOLOGY}

The paper has employed use of existing reviewed literature from research journals, conference proceedings and Medline digital library for discussions and determining the answers to the study objectives. The findings from existing literature from the journals were used in making scientific conclusions. 


\section{USE OF ICT'S IN MANAGEMENT OF MEDICAL LABORATORY SERVICES}

Various medical facilities whose ICT levels are fully implemented have proper ways of managing their records and functions; Electronic health (e-health) is an example of adopted systems, which are aversely used to manage the entire health facility records [15]

Currently well-adopted facilities have incorporated new technological systems such as; m-health, grid computing, Healthcare Information Systems.

Health Information Technology for Economic and Clinical Health (HITECH) Act, drafted and enacted in 2009 , is the main driver for the adoption of electronic health records (EHRs) and the use of such systems in increasingly productive ways. EHRs has a databases which stores all required patient records thus has realised improved health care services. The following subsystems has helped this tool achieve most of its intended functions this includes; clinical decision support system (CDSS), computerized physician order entry system (CPOE), and health information exchange (HIE). For attaining maximum utilization of the system in management of laboratory services, the subsystems must communicate with a laboratory information system (LIS). In addition, middleware and appropriate data analysis systems are important in improving test utilization practices (Hassan A. Aziz, 2017).

$>$ M-Health apps are nothing but mobile apps that support medical treatment and public health practices through the smartphone devices, patient monitoring gadgets, personal digital assistants (PDAs), and other types of wireless network devices. Some of the benefits of $\mathrm{m}$ health includes easy health tracking via health apps, apps that improve wellness, paperless medical documentation, revolutionizing physical examinations, apps are cost-saving (Collier, 2018).

$>$ Medical research using Grids: For plans on various challenges, affecting most laboratories is the huge amount of data, which requires powerful computing and data management capabilities to handle large amounts of heterogeneous data within a given facility.

$>$ Healthcare Information Systems: software solutions for appointment scheduling, patient data management, work schedule management and other administrative tasks surrounding health (Oliveira, 2018) .

\section{STATE OF ICT DEPLOYMENT IN MANAGEMENT OF MEDICAL LABORATORIES}

Like many other areas of healthcare delivery, laboratory services are experiencing an IT revolution. Laboratory experts that keep pace with emerging IT have found new, more efficient ways to communicate and provide services; educate themselves, their staff, and their clients; market their products; and manage data and information. Despite efforts to deploy ICT in health services by developing nations, most of them are faced by various challenges that have hindered the growth of technologies as compared to developed countries. Existing laboratory health information systems are drawn from developed countries (Press, 2019).

The use of electronic systems creates the opportunity to improve laboratory services. For instance, laboratory results tests can be influenced by drug use. Patient records could include all pharmaceuticals the patient is taking. The computer could then be programmed to identify cases in which the results are likely to be affected, and it may even be able to assist in the interpretation of test results and suggest appropriate actions to be taken (Press, 2019).

\section{$>$ Impact of ICT Use by Medical Laboratory Services}

Today it can be established that most health facilities are yearning to realise their objectives through the use of ICT's which is regarded as the backbone and future of information systems. Their scope is also extremely vast in such a way that Medical laboratories are taking advantage by embracing use of technology in their functions. Through advancements in technology, globally access to information should be made easier and this applies to all medical facilities (Jones, 2014).

In addition to this, certain nation's information should be able to flow smoothly due to faster growth of internet and related technology. Use of such technologies should be embraced by all laboratory experts and stakeholders within a facility (Jones, 2014). The constant access to stored information required for routine activities such as examining is very important for assessing and analysing laboratory requirements, this make the technologists aware of similar researches being carried out globally. We can generally allude that deployment of ICT's has impacted to a large extent in improving the quality of laboratory services in developing nations such as Kenya and globally. Deployment of technologies has realised electronic health functional, Patients samples are done faster and the results are accurate (Jill Fortuin, 2017).

The automation of laboratory services will ensure faster and convenient relaying of information among the staff in a facility. The Patients will also leverage on such deployments since most of them will become more selfreliant and responsible for their personal health. Due to real-time laboratory results, Patients who suffer from acute health related conditions can regularly monitor their health parameters and convey the results to relevant doctors on a regular basis thus both the doctor and patient are never out of touch (Simba, 2015). Full deployment of ICT's will ensure both the patients and doctors get on with their lives without the patient having to visit the doctor often but still keep track of the latest developments in patients' health.

\section{$>$ Modern ICT's used in medical laboratory services}

Most medical laboratory facilities that have embraced use of ICT's have been experiencing positive results brought about by major paradigm shifts by deployment of advanced technologies in the health facility scenario globally, and those countries belonging to the European 
Union. Modern systems have simplified access to provision of better health care in majority of the facilities irrespective of the physical location [19]. The introduction of technologies such as Telemedicine in health facilities today will impact more to our nation's service delivery. Telemedicine is a branch of medical care system where medical practitioners and patients can interact with each other over video conferences hence the experts in health matters can be able to analyse patients conditions in realtime through use of technology. Such advancements in ICT has provided better platforms for quality policy making in time, there are no barriers due to easier communication between the medical care providers and the public hence improving medical care services nationally[13]. Telemedicine as a system has shown that it is very beneficial to providers of medical equipment's since they can assess the demand based on the records and develop suitable instruments.

Globally, ICT use has enhanced the medical market to greater heights. Furthermore, ICT deployment empowers countries health care providers and stakeholders to expand their services all over the world, however, resent studies show that Technology has become a challenge in deployment of technologies such as telemedicine in developing countries due to higher cost and inadequate budget implications of changing from the current technologies to new. The success of technologies such as telemedicine will only depend both the healthcare delivery system and not as a stand-alone project (M Aqil Burney, 2010). If the concerned organs in our countries actualize this, then telemedicine should be fully implemented as a mainstream health services delivery system (Bali, 2018).

Currently, most of the laboratory facilities in developing nations are automating their services so that their experiments are real-time and accurate for better service delivery. The automated experiments have led to improved diagnosis and reduced costs of Medicare suggest that almost all primary care could be provided by physician extenders assisted by computer-driven diagnostic tools and support systems. Full implementation of such services will also ensure general reduced health-care costs that are extremely higher in developed nations (Bali, 2018).

\section{BARRIERS TO ADOPTION OF ICT'S IN MANAGEMENT OF MEDICAL LABORATORY SERVICES}

Most health facilities in Kenya are experiencing difficulties in the process of adopting to ICT's in management of laboratory services. The majority of health facilities do not have the capacity to purchase the required adopting ICT'S due to the following factors.

\section{$>$ ICT's Infrastructure}

Most facilities today are faced with poor ICT infrastructure due to Lack of strategy and funding of getting connectivity to the last mile within a given facility.

- There is Minimal infrastructure exhibited in various facilities in countries due to inadequate funding for such projects, poor planning for such projects due to lack of skilled personnel with knowledge or awareness of what should be available to countries in installing the correct technology for use.

- Most facilities are faced with the challenge of less content essential to enable a health facilities technological needs are achieved.

\section{> Inadequate ICT's Personnel}

- Most heath facilities are faced with Inadequate ICT personnel who can have the skills required to drive the needs in health sector thus impacting negatively on medical laboratory needs.

- There has been serious cases on the various skills required to deploy the relevant technology in a facility for example such skills in health informatics are very rare thus most institutions cannot offer services in that area.

- Field of ICT is still evolving since there are less skilled persons in Health IT

- More training should be done on staff in various facilities on the need to be aware and access deployed ICT's.

\section{> Inadequate cost of ICT's for health care facilities}

Most developing countries have experienced less funding which is not able to cater for the entire facility investment in ICT. This has been the norm with other various facilities within most developing nations with just a few attracting available funding to cater for all (WHO, 2004). Very few government owned facilities are fully equipped with health services and have or do not have working ICT systems deployed, un-reliable ICT infrastructure to enable inter-organizational transfers of data. Invariably, there is are no national health information and IT infrastructure to underpin the delivery of health care services, a lot has been done through research and the situations are changing for most developing nations are now deploying ICT and health plans have been made to factor in budgets for health infrastructure and ICT involment strategies WHO (2004) [13].

ICTs Investment for health is less advanced than expected in some facilities in Kenya today, this due to institutional, cultural, and financial factors. The financial factor is one that is common to other regions: effective use of ICTs in health will need funding at a higher level than is currently the case. Finding ways to blend private and public resources in ways that contribute to the development of improved; publicly accessible knowledge bases are key challenges [12].

Deployment of ICT services in healthcare have key benefits which must be identified, not only in monetary terms but also in terms of growth in access, quality of care, better return of resource utilization, better clinical and accurate laboratory results, user satisfaction, and improvement of the overall community health status. Given the available limited and finite resources to health decision makers, the right choices can be realised only by appraising 
the alternative options that carry most benefit, that is affordable and within budget plans. Unfounded vendordriven expectations of how the Internet will revolutionize health care have too often overshot their targets [11]. Overestimation of results and consequent unfounded expectations are common pitfalls. A common error has been to regard technology as the solution to logistical, administrative, and knowledge management problems of healthcare. The lesson to be learned for the use of ICTs in health is that technology can be justified economically only if organizations deploy it in a real practice environment and closely track how managers and direct care professionals are using it. This requires the stepwise development and implementation of processes and metrics to monitor productivity and impact.

However, other limitations will include the real threat of a digital divide is within the developing countries themselves. This arises from a number of sources. Most developing countries, an overwhelming majority of the population is likely to remain excluded from the benefits of new technologies. Even where physical access is available, inadequate education would ensure that most people did not have the same levels of competence or confidence to participate in the transformations in work practices and lifestyles as the urban and rural elites (Ouma N. K., 2009). Finally, increase in accessibility is exhibited thus the rapid changes in ICTs and their use would result in many of those who had had access initially falling behind in their ability to continue to use the benefits of the technologies.

\section{$>$ End- User's perceptions on ICT's Use in Health facilities \\ The Users' perceptions on a given technology can} affect how a new technology is conceptualized and if it will be accepted and fully implemented. According to related study sources that involved exploring hopes and fears in the deployment of electronic health, records in Bangladesh it was found that most actors are only afraid of using ICT in health sector based on their cultural perceptions about technology. The study noted that certain physicians have this thought that using information system for record management could be more time consuming, which would negatively influence the time they could spend with patients which is not the case (Nzuki, 2016). For the successful deployment technologies such as e-Health, in developing countries various stakeholders must change their attitudes on e-Health. Patients must be ready to allow their information to be shared using ICTs, they should be able to use mobile devices to search health information and must develop trust towards electronic medical records. All medical practitioners must perceive ICTs positively by encouraging each other to use them in the provision of better health services. Those nations that might experience adoption related challenges with technologies, should seek solutions to addressed rather than dismissing the entire concept of information systems [12].

In order to fully implement ICT's development, it is advisable that developing nations must be in the forefront in raising awareness of ICTs in health sectors through mobilizing organizing to train staff and stakeholders through seminars or conferences [5]. Other barriers that have equally affected this adoption includes; Lack of formal organizational structure to deliver telemedicine services is the biggest barrier for the development of telemedicine services in any country, Lack of accreditation or regulatory bodies, lack of trained champions . Some organisations have not implemented the Training of staff on new technology which is an important part of skill development and the organizations should develop a training schedule to train health professionals for smooth delivery of telemedicine services.

\section{> Medical laboratory ICT's adoption Levels}

ICT deployment levels for medical laboratory services has previously been rated as not fully implemented among developing countries due to lack of skilled personnel in IT, awareness amongst the health services users. However, this indication has since improved and changed adversely due to the advancements in technology where there is access and use of ICT's by the users in health facilities which most of them are currently approaching full implementation and deployment to a higher level. In countries that have assimilated ICT training for practitioners and general users, ICT acceptance and adoption deployment of various systems is relatively high. Training and awareness of all stakeholders boosts acceptance levels and confidence level as users are able to overcome technophobia while relating usage to expected benefits. There is correlation between ICT skills and deployment of ICT's as alluded by [5] who points out that inadequate ICT skills in the health sector in Kenya explains the low adoption levels of e-Health.

\section{$>$ ICT Confidentiality and Security Concerns in Health}

Today as we try to adjust to the new trending technologies there are serious challenges brought about by such technologies. This challenge includes information security matters that affect our privacy and confidentiality. Confidentiality and privacy as an issue has not been much addressed in research studies and being key factors that affect deployment of ICT's there is need to explore more on this matter. All users of any system need to be assured of the protection and confidentiality of their data in case we really want to achieve full deployment. It is important that the privacy and security of electronic health data be safeguarded to gain confidence amongst healthcare stakeholders [6]. Previous studies on developed nation's security for example the case of Tanzania; ICTs are still exposed to security breaches due to vulnerabilities in the systems themselves. Moat the studies do not indicate how this should be solved, however, this paper will recommend that the issues concerning privacy and security of health information should be controlled by using known security strategies now that we know the main causes of such breaches. Most of our health facilities have inadequate funds for helping them install required ICT infrastructures, lack of skilled ICT personnel in security as a field that is still evolving; this requires the organisations and all stakeholders to train staff and all users on issues of security [14]. 


\section{MODERN ICT'S DEPLOYED TO IMPROVE MANAGEMENT OF MEDICAL LABORATORY SERVICES IN KENYA}

\section{$>$ Electronic Health}

In order to achieve better service delivery in any health facility, there has to be proper management of the facility. Deployment of ICT in the service will foster and affect the facility daily functions, in addition to these organisations such as (WHO) have been mandated in ensuring better health care delivery for all. One of the recent commonly used ICT's is e-health. World Health Organization (WHO) defines the term Electronic-Health as a combination of both electronic tools of relaying messages and use of modern Technologies in the health sector. The main role of Electronic -Health is to ensure that the right information is provided and relayed in a secured manner to the right persons at the right place and time, in an electronic form in order to support the delivery of quality and efficient healthcare to all[13], [19]. Electronic-Health can be viewed as one of the main essential infrastructure underpinning information exchange between all players in the Kenyan health care system and as a key enabler and driver of improved health outcomes. When ElectronicHealth is fully deployed, a health facility will grow its information management system thus there will be more effective responds from the facility to the health care needs of individuals and communities where services such as lab results will be realised in time.

\section{$>$ Mobile-Health Systems (MHS) and Personal Health System (PHS)}

The use of portable electronic devises in health has increased and its growth is tremendous due to the faster growth in technology. Recent advances in technologies such as wireless networks and mobile computing have affected the way practitioners communicate today since information is now a touch of a button to them. New emerging concepts like mobile- health systems (MHS) and Personal Health System (PHS) if implemented are expected to revolutionize the way healthcare services are delivered. In order for this technology to fully execute its functions, Mobile-Health incorporate other functional tech tools such as mobile computing, medical sensors, and wireless communication technologies for delivering healthcare in a non-restrictive manner. These systems are safety critical systems intended for use by the public and are therefore characterized by especially strict requirement relating to safety, security, correctness, reliability, and adaptability and user friendliness. Another new technology is the Personal Health System (PHS), which is concerned with the patient's individual prevention, the patient's treatment and well-being procedures available through the healthcare system. The patient is put at the center of the delivery process. For these systems to be fully operational globally more research is being done in this areas [19].

\section{$>$ Pervasive Healthcare}

This technology will ensure that there is Healthcare to anyone, anytime, and anywhere by removing locational, time and other restraints while increasing both the coverage and the quality (Varshney U., 2011).

\section{$>$ Wearable sensor devices}

There are research trends about the wearable sensor device that measures various bio-signals and provides healthcare services to users using e-Health technology. Such technologies will simply be adopted and work better in any developing nations if health care as a function is well planned and budgeted for. (Lee B. L. C., 2017).

\section{$>$ Intelligent Systems}

Many other technologies have to be integrated to enhance better performance for entire systems such as electronics health. A good example of such technology is use of intelligent systems in physiological signal monitoring for electronic-Health is a current and a trending technology. This system can help medical practitioners to monitor and analyze human physiological signals effectively and immediately thus help reduce medical costs and hospital visits. For the realization of full support to a given facility key functions just apart from the labs and other key areas, there are other functional areas of the facility that are too administrative that require planning for making key decisions of a given facility. Technologies such as decision support systems will be the answer to all the current and future plans of a facility such decisions will be affecting well and affect the entire organisations future both positive and negative. I do support the incorporation of decision support systems to our current systems. To fully achieve this more research has to be done on the technology to realise future adoption (Chen C. , 2012).

\section{$>$ Electronic-Health Technologies for the Elderly}

The elderly people are the most important to our society today and proper medical care is required to sustain since the majority are of them are in-need. To manage the world's population ages which has been increasing in developed nations due to existing health-care, there is growing interest in solutions for the in-home care of the elderly as well as for the care of people with diseases such as Alzheimer's, Parkinson's and other disabilities or traumas that have been diagnosed to mostly affecting the elderly (Geyong M. M. A., 2009). This has spurred research interest in e-Health systems that integrate healthcare devices and services as well as identifying solutions for their secure communication within the home environment in order to help this group of senior citizens live more independently in their homes. Tele-monitoring and remote healthcare are two ICT techniques that promise to deliver cost-effective long-term healthcare services to the aging if fully implemented. The health care for the elderly in developing countries is not the best, the elderly people in this countries life expectancy is lesser compared to the developed due to the use of available medical care policies and infrastructure. 


\section{$>$ Telemedicine, Health Telematics}

Telemedicine is the delivery of health care services, where distance is a critical factor, by health care professionals using ICTs for the exchange of vital information for diagnosis, treatment and prevention of key disease and injuries, research and evaluation, and for the continuing education of health care providers, all in the interest of advancing the health of individuals and their communities [19]. World Health Organisation describes health telematics as a composite term for health-related activities, services and systems, carried out over a distance by means of ICTs, for the purposes of global health promotion, disease control, and health care, as well as education, management, and research for health. More restrictive terms that are part of telemedicine include teleconsultation, telediagnosis, remote second opinion, teleradiology, telesurgery, telecare, teleducation and teletraining

\section{$>$ Convergence and Combination of Technologies}

The experts in health and IT. Have proved the use of several technologies to achieve a given result The combination of two or more technologies in developed nations has shown better results and service to all. An earlier report by DFID indicated that Health services can be improved also through Convergence and combination of technologies this can help many developing countries improve health services activities. It has long been recognized, as a DFID report in (2001) noted, that a combination of new ICTs and traditional media can provide the widest coverage and ensure that those excluded from education by virtue of poverty, gender, geographical remoteness or conflict are not excluded[15] in Information communication technologies, poverty and empowerment program. Social development department, dissemination Note 3, London: DFID (2001). When making a conclusive choice on the best technology to use should be determined mainly by the specific local context and demand. In Kenya, organisations such as AfriAfya has been exploring various innovative ways of combining several ICTs in different field setting, this has since yielded better results as demonstrated in those facilities where the programs were done. Its experience underlines the importance of undertaking information-needs assessments to the stakeholders and finding out what information people want rather than simply supplying them with what is available. It was evident that despite the large amount of information available on various electronic sources, very little is directly suitable for dissemination to poor communities due to poor packaging thus there is need for repackaging to ensure local suitability and relevance[19].

\section{$>$ Picture Archiving and Communication System}

A picture archiving and communication system (PACS) is an electronic and ideally filmless information system for acquiring, sorting, transporting, storing, and electronically displaying medical images. This technology captures and integrates diagnostic and radiological images from various devices (e.g., X-ray, MRI, computed tomography scan), stores them, and disseminates them to a medical record, a clinical data repository, or other points of care (M Aqil Burney, 2010).

\section{CONCLUSIONS}

The paper has discussed in detailed the state of ICT deployment in medical laboratories in Kenya, challenges facing the deployment and ICT technologies deployed in the management of medical laboratory services. From the literature sources in this paper, we can establish that Kenya has deployed use of ICT's in various health facilities however; there are some facilities, which are experiencing challenges in the deployment process. The study establishes key challenges to the deployment of ICT's in Kenyan medical laboratory health services through analysis realised by the findings from the literature review constraints on realizing the potential of ICTs for improving health conditions, there is a need for a careful and managed approach to the development of ICTs health infrastructure, health information systems adequate resources for developing countries. Despite its rapid growth, the ICT sector in most developing countries is small and the effect of its growth on the rest of the economy is limited. There is the prospect of a sharply widening digital divide even within developing economies, developing nations lack key plans or the strategies to be used in the deployment process, the drafting and implementation process of putting in place key policies and developing important strategies to enable them meet the concerns of fully deployment of ICT's in the management of medical laboratory services is key. The paper further highlighted the following modern ICT's adopted to improve management of health services in Kenya ; Telemedicine, Health Telematics ,Convergence and Combination of Technologies, E-Health technologies for the elderly, Wearable sensor devices, M-Health Systems and E-Health.

\section{REFERENCES}

[1]. ao, J., Fan, S.-C., \& Yang, B.-S. (2009). Custos Remote on-demand healthcare aided with wireless sensors and mobile phones. IEEE International Conference on Systems, Man and Cybernetics.

[2]. Bali, S. (2018, October 18). Barriers to Development of Telemedicine in Developing Countries. Retrieved from Open access peer-reviewed chapter: https://www.intechopen.com/books/telehealth/barriers -to-development-of-telemedicine-in-developingcountries

[3]. care, I. H. (2016, June 13). (ICT) Helps Improve Health Care (ICECI). Retrieved May 6, 2016, from http://iceci.org/documentations/information-andcommunication-technology-ict-helps-improve-healthcare

[4]. Care, I. H. (Care, I. H, June 13). ICT Helps to Improve Health Care. Retrieved October 18, 2018, from http://iceci.org/documentations/information-andcommunication-technology-ict-helps-improve-healthcare 
[5]. CHAFA, M. V. (2016). Application of Information and Communication Technology for Preventive of Communicable Disease by Public Health Workers in States of Northern Nigeria. Samaru Journal of Information Studies.

[6]. Chen, C. (2012). Web-based remote human pulse monitoring system with intelligent data analysis for home health care. . Expert Systems with Applications(ACM), 38(3), 43-47.

[7]. Chen, C.-M. (2011). Web-based remote human pulse monitoring system with intelligent data analysis for home health care. International Journal of Expert Systems with Applications(ACM), 38(3).

[8]. CN Kamau, S. O. (2010). The Impact of E-Resources on the Provision of Health and Medical Information Services in Kenya. Journal of electronic resources in medical.

[9]. Collier, J. (2018, September 12). M-Health: What is it, and how can it help us? Retrieved December 30, 2019 , from https://www.medicalnewstoday.com/articles/322865.p $\mathrm{hp \# 1}$

[10]. David Nzuki (Ph.D), D. M. (2014). Determinants of Electronic Health in Developing Countries. international journal of arts and commerce, 3(3).

[11]. Fonseca T., G. C. (2009). Autom Acqui \& elect pat recor ststems. Journal of medical systems.

[12]. Gerami, K. \&. (2010). Can Information and Communications Technology Applications Contribute to Poverty Reduction? . Information Technology for Development, 10, 73-84.

[13]. Geyong M., M. A. (2008). Wireless connected home with integrated secure healthcare services for elderly people. ACM Proceedings of 1 st International Conference on PErvasive Technologies.

[14]. Geyong M., M. A. (2009). Wireless connected home with integrated secure healthcare services for elderly people. ACM Proceedings of 1st International Conference on PErvasive Technologies. UK.

[15]. Hassan A. Aziz, P. M. (2017). Health Informatics Tools to Improve Utilization of Laboratory Tests. Laboratory Medicine, Volume 48, Issue 2, May 2017, Pages e30-e35, https://doi.org/10.1093/labmed/lmw066, 48(2), 30-35.

[16]. Hofmann. (2002). Is there a technological imperative in health care? Int J Tech Assess Health Care, 18(3), 675-689.

[17]. InfoDev. (2006, May 31). Improving Health, Connecting People. Role of ICTs in the Health Sector

[18]. Jone V., R. A. (2004). A formal MDA approach for mobile health systems. 2nd European Workshop on Model.

[19]. Jones, R. G. (2014). Informatics and the Clinical Laboratory. Journal the clinical biochemical reviews, 177-192.

[20]. Juma, K. (2012). Current Status of E-Health in Kenya and Emerging. International Journal of Information and Communication Technology Research, Volume 2 No. 1(1).
[21]. Kenya, G. o. (2011). Kenya National E-health strategy 2011-2017. Mministry of Health.

[22]. Kilwake J, M. N. (2012). Current Status of E-Health in Kenya and Emerging Global Research Trends. International Journal of Information and Communication Technology Research, 2(1).

[23]. Kilwake J, M. N. (2012). Current Status of E-Health in Kenya and Emerging Global Research Trends. International Journal of Information and Communication Technology Research, 2(1).

[24]. Laufman. (2002). Are engineers unsung heroes of medical progress. Biomed Instrum Technology, 36(5), 325-334.

[25]. Laufman. (2010). Are engineers unsung heroes of medical progress? Journal of Biomed Instrum Technology, 36(5), 325-334.

[26]. Lee B., L. C. (2017). Implementation of Wearable Sensor Glove using Pulse-wave Sensor. 3rd IEEEEMBS International Summer School and Symposium on Medical Devices . . Germany.

[27]. Lee B., L. C., \& Lee M., L. Y. (2006). Implementation of Wearable Sensor Glove using Pulse-wave Sensor. Proceedings of the 3rd IEEEEMBS International Summer School and Symposium on Medical Devices .

[28]. M., D. N. (2016). Determinants of Electronic Health in Developing Countries. International Journal of Arts and Commerce, 3(3), 45-49.

[29]. Mndeme, N. \&. (2010). Power Tensions in Health Information System Integration . Electronic J, inf sys dev countries, 43(4), 1-19.

[30]. Mndeme, N. (2011). Power Tensions in Health Information System Integration . Electronic Journal of information systems for developing countries, 43(4), 1-19.

[31]. Oliveira, M. S. (2018). The Impact of mHealth Interventions: Systematic Review of Systematic . MIR Mhealth Uhealth. 2018 Jan; 6(1): e23.Published online 2018 Jan 17. doi: 10.2196/mhealth.8873, $6(23)$.

[32]. Omotosho, A., Emuoyibofarhe. (2011). ICTs in Health Care Delivery Systems - A Fra. In proceedings of International Conference on ICT. Ota.

[33]. Organization, W. H. (2006, May 5). E-Health tools and Services. Global Observatory for eHealth, pp. 15.

[34]. Ouma, N. K. (2008, April 16). he impact of Eresources in the provision of health and medical information services in Kenya. E-resources in the provision of health and medical information services.

[35]. Ouma, N. K. (2009). The impact of E-resources in the provision of health and medical information services in Kenya. . E-resources in the provision of health and medical information services, 12(5), 123-128.

[36]. Petrova G., S. M. (2009). Architectural Models for realization of web-based Personal Health Systems. ACM ,International Conference on Computer Systems and Technologies. 
[37]. Sahay, M. \&. (2005). Role of Communication Practices in the Strengthening of Counter Networks. Information Technology for Development, 11(3), 207225. .

[38]. Sahay, M. (2010). Role of Communication Practices in the Strengthening of Counter Networks. Information Technology for Development, 11(3), 207225.

[39]. Simba, D. O. (2015). Application of ICT in strengthening health information systems in developing countries in the wake of globalisation. journal of African Health Sciences 2015; 4(3) 194198, 194-198.

[40]. Varshney, U. (2005). Pervasive Healthcare. Communications of the Association for Information Systems, 16(3).

[41]. Varshney, U. (2011). Pervasive Healthcare. Communications of the Association for Information Systems, 16(3), 34-39.

[42]. Watson. (2003, May 14). The future role of diagnostic testing,International Hospital Federation. Retrieved June 5, 2016, from http://www.hospitalmanagement.net/informer/manage ment/diagnostics1/index.html Weigel

[43]. Watson. (2016, June 5). he future role of diagnostic testing,International Hospital Federation. Retrieved $\begin{array}{llll}\text { October } & 18 \quad \text { 2018, from }\end{array}$ http://www.hospitalmanagement.net/informer/manage ment/diagnostics1/index.html Weigel 